\title{
Coupled hydro-meteorological modelling on a HPC platform for high-resolution extreme weather impact study
}

\author{
Dehua Zhu ${ }^{1, a}$, Shirley Echendu ${ }^{1}$, Yunqing Xuan ${ }^{1}$, Mike Webster ${ }^{1}$, and Ian Cluckie ${ }^{1}$ \\ ${ }^{1}$ College of Engineering, Swansea University Bay Campus, Swansea, SA1 8EN, UK \\ ${ }^{a}$ now at: School of Hydrometeorology, Nanjing University of Information Science and Technology. Nanjing, 210044, China \\ Correspondence to: Dehua Zhu (d.zhu@nuist.edu.cn)
}

Received: 21 March 2016 - Published in Hydrol. Earth Syst. Sci. Discuss.: 24 June 2016

Revised: 9 November 2016 - Accepted: 10 November 2016 - Published: 29 November 2016

\begin{abstract}
Impact-focused studies of extreme weather require coupling of accurate simulations of weather and climate systems and impact-measuring hydrological models which themselves demand larger computer resources. In this paper, we present a preliminary analysis of a high-performance computing (HPC)-based hydrological modelling approach, which is aimed at utilizing and maximizing HPC power resources, to support the study on extreme weather impact due to climate change. Here, four case studies are presented through implementation on the HPC Wales platform of the UK mesoscale meteorological Unified Model (UM) with high-resolution simulation suite UKV, alongside a Linux-based hydrological model, Hydrological Predictions for the Environment (HYPE). The results of this study suggest that the coupled hydro-meteorological model was still able to capture the major flood peaks, compared with the conventional gauge- or radar-driving forecast, but with the added value of much extended forecast lead time. The highresolution rainfall estimation produced by the UKV performs similarly to that of radar rainfall products in the first 2-3 days of tested flood events, but the uncertainties particularly increased as the forecast horizon goes beyond 3 days. This study takes a step forward to identify how the online mode approach can be used, where both numerical weather prediction and the hydrological model are executed, either simultaneously or on the same hardware infrastructures, so that more effective interaction and communication can be achieved and maintained between the models. But the concluding comments are that running the entire system on a reasonably powerful HPC platform does not yet allow for real-time simulations, even without the most complex and demanding data simulation part.
\end{abstract}

\section{Introduction}

Extreme precipitation with great intensity and the subsequent flash flooding events arising from rivers and mountainous watersheds often lead to considerable economic damage and casualties, because water levels can react extremely quickly within rather limited warning lead time (flash flooding). Therefore, the evaluation of potential flooding risks in extreme weather conditions, and the corresponding protection measures required, demands accurate short-term flood forecasting, and more often very short lead-time forecasting - termed "nowcasting" (Cloke and Pappenberger, 2009).

Understandably, hydrological models together with hydraulic models play a key role in predicting runoff, river flow, and possible inundations. However, the lead time, which is crucial for hazard mitigation and evacuation, is often highly limited in such a classic model chain configuration, since, the lead time is basically then the travelling time of flood water. It is therefore other means of providing rainfall estimates with extra lead time (e.g. weather radar observations) which have become increasingly essential in flood forecasting under extreme weather conditions (Zhu et al., 2014). However, it has also been recognized, for example by Golding (1998) and Smith and Austin (2000), that the performance of radarbased rainfall nowcasting deteriorates rapidly when the lead time goes beyond $0.5 \mathrm{~h}$. Then, the combination of radar nowcasting and hydrological forecasting is reduced to that of a normal model, or even worse. In fact, early attempts, whilst using the NIMROD radar rainfall product, already introduced a rainfall forecast from numerical weather prediction models to compensate for this shortcoming. 
The fast development of HPC (high-performance computing), as well as that of NWP (numerical weather prediction) models, has since given rise to the use of NWP, either directly or indirectly in hydrological simulations, in an effort to push hydrological forecasting beyond the limit of the rainfallobservation time horizon. This link between two different modelling disciplines is often referred to as model coupling. The resulting coupled meteorological-hydrological models appeared from the beginning of the 21st century, being initially focused on flash-flood forecasting, and later extended to handle climatic-hydrological coupling. This has facilitated many climate-change impact studies on water resources that rely heavily on the use of climate projections or simulations. Nevertheless, the linkage between the meteorological and hydrological models is scientifically challenging due to differences in model structures and issues of incompatible units (use of different scales in time and space). This is encapsulated, in particular, in the task of how best to transform and regionalize global climate scenarios, with spatial resolutions of $1000-10000 \mathrm{~km}^{2}$, to hydrological mesoscale catchments of $10-1000 \mathrm{~km}^{2}$.

Simulation with meteorological-hydrological coupling in high spatial and temporal resolution is a comparatively new field of hydrological research, yet some pioneering work has recently appeared. In order to analyse the prediction of selected events characterized by peak flows, Westrick et al. (2002) proposed a hydrometeorological forecasting system for mountainous watersheds by coupling the Penn State-NCAR Mesoscale Meteorological Model (also known as MM5 for brevity; Dudhia, 1993; Grell et al., 1994) in $4 \times 4 \mathrm{~km}^{2}$ resolution and the distributed hydrological model DHVSM (Wigmosta et al., 1994). Jasper et al. (2002) compared the hydrological performance of radar and gauge measurements with five different high-resolution NWP models and grid-cell sizes between 2 and $14 \mathrm{~km}$. This work covered the prediction of peak flows on the alpine Ticino-Toce watershed, using the distributed hydrological model WaSiM (Schulla and Jasper, 2000). The results suggest that the accuracy and consistency of NWP rainfall in hydrological applications heavily depend on their process modelling at all scales of model nesting. Particularly so, as inaccuracies introduced by downscaling of precipitation from NWP models can lead to large differences in the predicted hydrological results, especially during extreme convective storm periods. Kunstmann and Stadler (2005) coupled (in a one-way manner) the mesoscale meteorological model MM5 with the distributed hydrological model WaSiM. The meteorological re-analysis data were dynamically downscaled with MM5 grid-cell sizes from 100 to $2 \mathrm{~km}$ using four nests. Findings show that the MM5-based interpolation of precipitation yielded $21 \%$ less total yearly precipitation in the catchment area, compared to the station-based interpolation. Yarnal et al. (2000) linked a high-resolution meteorological model (MM5 at $4 \mathrm{~km}$ resolution) and a suite of coupled hydrological models in the Susquehanna River Basin Experiment
(SRBEX). This work points out that the coupled model has to confront several issues, such as physics and parameterizations, for a mesoscale atmospheric model to match the timescales of climate coupled to the hydrological, meteorological and climatological process models with different scales, and accordingly the immense computational needs. Xuan et al. (2009) also indicated that the inaccuracies and uncertainties in NWP could propagate to the downstream hydrological models, and they proposed to use an ensemblebased approach, together with effective bias correction, to mitigate this problem.

The majority of the studies cited above have been relying on the use of the so-called downscaling of large-scale NWP results using regional meteorological model such as MM5. These studies are often conducted in an offline manner where hydrological modellers have hardly any control of NWP except the meso-scale one used for downscaling. However, the work presented in this paper not only focuses on the performance of coupled high-resolution meteorologicalhydrological simulations for extreme storm events on a HPC platform. It is also aimed at exploring the potential of building and running fully coupled NWP-hydrological forecasts on a single computer platform, and therefore being able to obtain first-hand knowledge on fully integrated hydrometeorological modelling. As such, we did not apply the meteorological model in forecasting mode, but used hindcasting mode instead, to test the model performance and benchmarking over several selected historical events.

One of the main challenges faced in coupled NWPhydrological model simulation, or operational forecasting, is their reliance on computationally implementing NWP. In turn, this necessitates the use of HPC, a procedure which can be performed in two different fashions: firstly, through an offline approach, where the hydrological model receives data that are generated from NWP beforehand (e.g. the data disseminated from various national meteorological centres), and secondly through an online mode, where both NWP and the hydrological model are executed, either simultaneously or on the same hardware infrastructures, so that more effective interaction and communication can be achieved and maintained between the models. Most existing studies have adopted the former approach to ease technical demands on HPC as well as on NWP.

In contrast, this study takes a step forward to identify how the latter approach can be used, once HPC installation has been resolved. Moreover, it is worth noting that this experiment of a fully coupled NWP-hydrological forecast is preliminarily designed to be a one-way coupling system in this study, which will form the basis for extension into a two-way coupling system, which will be developed further in the future. 


\section{Materials and methods}

In this study, the principal goal of the experiment has been to simulate the river basin response to extreme storm events, by linking a semi-distributed hydrological HYPE model to the UK Met Office Unified Model (UM) at a much finer spatial scale $(1.5 \mathrm{~km})$. The combined high-resolution oneway driven model experiments generate runoff hydrographs for three extreme flood events, which occurred in the Upper Medway catchment $\left(220 \mathrm{~km}^{2}\right)$ located south of London in the UK (see Fig. 1).

The catchment elevation varies between 30 and $220 \mathrm{~m}$ above mean sea level and the majority of slopes range from 2 to $8^{\circ}$, which makes up around $70 \%$ of the whole catchment. This suggests that the main topography of the Upper Medway catchment is made up of small hills surrounding the flat, low-relief, low-lying area without much variation of elevation. The land use in the catchment can be simplified and described as permanent grass (over $95 \%$ ). The major soil types in the Upper Medway catchment can be categorized as silty loam and clayey silt, according to the National Soil Resources Institute (NSRI) data. The geology of the catchment is a mixture of permeable (chalk) and impermeable (clay) and the dominant aquifers consist of the Ashdown Formation and the Tunbridge Wells Formation of the Hastings Group. The saturation-excess mechanism is the major runoff generation process in the catchment.

In such model experiments, two different sets of meteorological input data were used: (1) surface observation data from station measurements and from weather radar estimation, and (2) forecast rainfall data from high-resolution UM simulation suite, UKV, with grid-cell sizes of $1.5 \mathrm{~km}$. The experiments were designed as follows: (1) selecting representative storms and hydrographs for simulation, (2) simulating these storms using the high-resolution UKV simulation model, and (3) modelling the river-basin response to the simulated storm events using the HYPE hydrological model.

One notes that Met Office has used the operational highresolution UK $1.5 \mathrm{~km}$ model (UKV) under the New Dynamics algorithm specification. This introduces nested operations, through parallel suites PS30 and the time periods of interest. As such, this consists of a global $25 \mathrm{~km}$ simulation, followed by a North Atlantic-European $12 \mathrm{~km}$ simulation, and finally, a UKV $1.5 \mathrm{~km}$ simulation. Each such simulation stage provides the necessary lateral (spatio-temporal) boundary conditions for the regionally refined subsequent stage.

Rainfall observations from weather radars were also introduced in this study to check the UKV output, since rain gauges are point-based and the radar rainfall can provide well represented rainfall distribution. Moreover, the comparison with UKV input through a hydrological model can be drawn, in terms of streamflow differences.

The rain-gauge measurements are collected from nine real-time, tipping-bucket rain gauges (TBRs) operated by the UK Environment Agency (EA). Figure 1 shows the loca- tions of the rain gauges (circles) and the flow gauges (triangles) on the catchment. And all the flow comparisons in this study were carried out at the Chafford flow gauge close to the catchment outlet.

The radar rainfall estimates used in this study are extracted from the UK NIMROD composite data set. This has been provided and quality-controlled by the UK Met Office using the lowest available scan. It has been adjusted against available rain-gauge measurement and undergone extensive processing to correct for various sources of radar error. Such radar error would include noise, clutter, anomalous propagation, attenuation, occultation, and "bright band" and orographic enhancement. Therefore, these high-resolution radar composite rainfall estimates incorporate the latest UK Met Office processing algorithms to account for the different sources of errors in the estimation of precipitation using weather radars (Harrison et al., 2000). This implies that this data set is the best possible estimate of rainfall available at the ground level in the UK (i.e. it is the most error-free).

More details in regards to the properties of this catchment and data description used in this study, such as topography, vegetation, and soil types, as well as the availability of a hydrological data set, have been detailed in Zhu and Cluckie (2012) and Zhu et al. (2014).

\subsection{UKV model configuration and implementation}

The Unified Model is an atmospheric predictive numerical modelling software, offered by the UK Met Office and written in FORTRAN. Here, its output is coupled with a hydrological model for the purpose of accurate flood and extreme storm prediction. The UM was built on Archer hardware, with specification as a Cray XC30 MPP supercomputer and with up to 4920 compute nodes, each having a two 12-core Intel Ivy Bridge series processor, providing a total of 118080 processing cores. Each node has 64 GB memory, with a subset of large memory nodes possessing $128 \mathrm{~GB}$.

Further to the successful build and implementation of the UM, output from the various implementations has been validated against results derived from other HPC architectures. The UM features a new dynamics algorithm, which is based on a semi-implicit, semi-Lagrangian formulation, that uses a common finite-difference scheme for the fully compressible, non-hydrostatic Euler equations, discretized on a latitudelongitude grid. The algorithm is designed around a matrixbound approach that is used to solve the semi-implicit aspects of the scheme.

The high-resolution simulation was achieved using the UKV suite which is a regional configuration of the UM, derived from operations through Parallel Suites (PS30), which consist of three nested domain simulations: a global $25 \mathrm{~km}$ simulation, a North Atlantic-European (NAE) $12 \mathrm{~km}$ simulation, and a UKV $1.5 \mathrm{~km}$ simulation. The Global N512L70 problem suite is discretized into approximately $25 \mathrm{~km}$ midlatitudes, upon a $1024 \times 769$ grid. There are 70 model lev- 


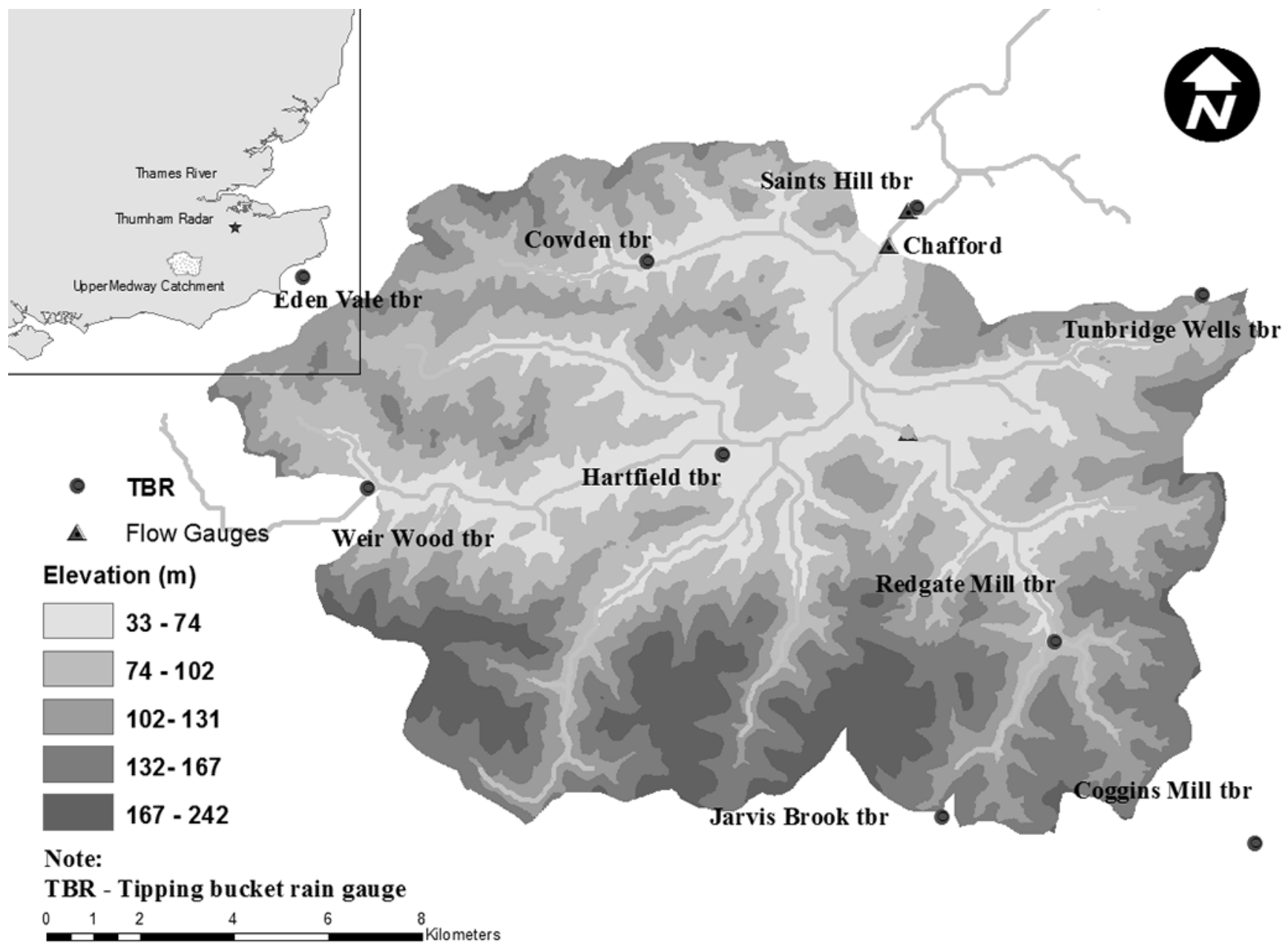

Figure 1. Map of rain gauges and flow gauge locations on the Upper Medway catchment (source: Zhu and Cluckie, 2012).

els vertically and a time step of $10 \mathrm{~min}$ is used. The regional NAE problem suite has a resolution of $12 \mathrm{~km}$, across a $600 \times 360$ grid. The NAE suite also has 70 vertical levels but the time-step choice is $5 \mathrm{~min}$. Finally, the regional UKV is set at $1.5 \mathrm{~km}$ resolution over a $622 \times 810$ grid with a time step of $50 \mathrm{~s}$.

UKV model implementation requires a few events for model run. This includes an initialization date and a number of subsequent time-duration periods, i.e. 3, 6, 8, and 12 days. A selection of 8-day start dumps was used in this study, requested from ECMWF or the Met Office. The Met Office holds start dumps to a back-date of up to 5 years only; prior to that, start dumps would need to be obtained from other sources.

The steps of the UKV process in the overall procedure are to run as follows: first, the global reconfiguration and forecast; second, the European reconfiguration and forecast; and finally, the UKV reconfiguration and forecast. These independent simulation steps are all dynamically linked through lateral boundary conditions (LBCs), and regionalization of a start dump. With the start dump reconfigured for a UM input file format (global region), this is then utilized to initialize the global, European and UKV reconfiguration and to obtain an additional start dump for the forecasting stage. In turn, the global forecast is run to obtain lateral boundary conditions for the European stage, whilst the European forecast provides lateral boundary conditions for the UKV.

The UKV model outputs were also on a rotated longitudelatitude grid, whose resolution is not constant, with small deviations from $1.5 \mathrm{~km}$ depending on the locations. The data were further projected onto the National Grid Reference Grid to become comparable with other sources of data, such as the weather radar rainfall observation from the NIMROD system. A nearest-neighbour interpolation was used to produce the evenly distributed grid data after projecting.

\subsection{The configuration and calibration of hydrological model HYPE}

Whilst many hydrological models could have been selected (for example see Zhu et al. (2014)), an open-source model - 
HYPE (Hydrological Predictions for the Environment) - has been selected in this study to avoid reliance on commercial modelling packages. HYPE is developed at Swedish Meteorological and Hydrological Institute (SMHI), with a focus on integrating water and water quality throughout the model compartments and predictions in ungauged catchments with large model set-ups, e.g. across Europe. It is a dynamical model forced with time series of precipitation and air temperature, typically on a daily time step. Forcing in the form of nutrient loads is not dynamical. Examples of HYPE applications include atmospheric deposition, fertilizers, and waste water.

The HYPE model is able to predict water and nutrient concentrations in the landscape at the catchment scale. Its spatial division is related to sub-catchments and corresponding characteristics, including land use, vegetation, soil type, and elevation. Within a particular catchment, the model will simulate water content in different compartments, including soil moisture, shallow groundwater, rivers, and lakes.

The default time step in HYPE is daily, but it can be reduced to hourly, which is normally specified in the input data set, such as precipitation. Since there is no 2-D surface runoff algorithm built in the HYPE model, it is in principle a lumped model. However, spatial variations can be accounted for by portioning the catchment into smaller sub-catchments. In this respect, the simulated precipitation was processed as the catchment average rainfall before being fed to the HYPE model.

The winter flood event, which took place from 6 December 2003 to 28 February 2004, was used for model calibration, carried out using $1 \mathrm{~h}$ time step rain-gauge measurements and parameterized with the streamflow observation at the catchment outlet. In order to achieve the best fit between observed and modelled flow, the model parameters were calibrated in simulation mode using a mixture of manual and automatic parameter adjustment, according to their functionalities in the model.

First, all the parameters went through an initial manual sensitivity analysis, to choose those worthy of further automatic parameterization. In this study, the maximum amount of percolation (mperc1, mperc2) in soil layers needs to be calibrated for percolation to occur. In addition, the soil-typerelated parameters, such as the available storage of water in the soil and the runoff coefficient of the topsoil layer (rrcs1), are sensitive in the model. And the peak velocity of flow in rivers (rivvel) determines the peak flow delay in the model, which also needs to be calibrated. After the sensitive parameters are selected, the progressive Monte Carlo simulation was employed to reduce the parameter space in stages and finally determine the calibrated parameters for later rainfall-runoff comparisons.

The soil properties setting is critical in HYPE model. Figure 2 shows the model calibration performance with single soil type (SST) and multiple soil type (MST) settings. The soil types and the corresponding properties for the Upper

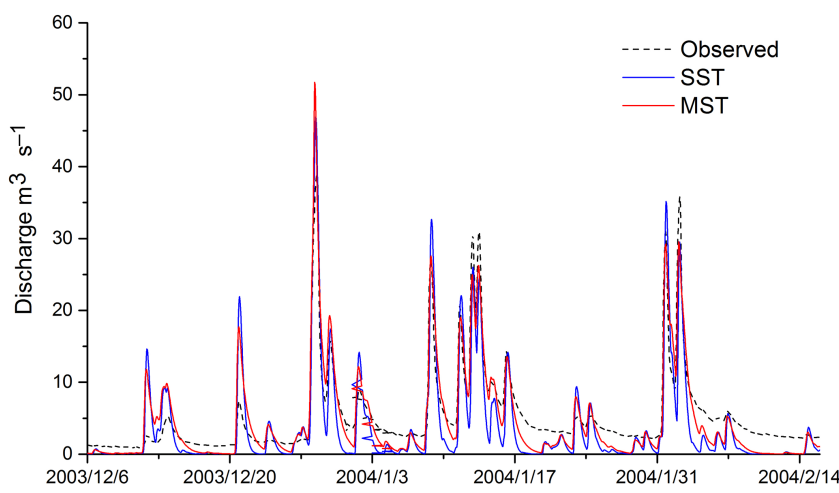

Figure 2. The comparison of model calibration with different soil settings.

Table 1. Soil properties for corresponding HOST number.

\begin{tabular}{lrrrr}
\hline HOST & $\begin{array}{r}\text { Water content } \\
\text { at saturated } \\
\text { condition }\end{array}$ & $\begin{array}{r}\text { Field } \\
\text { capacity }\end{array}$ & $\begin{array}{r}\text { Wilting } \\
\text { point }\end{array}$ & $\begin{array}{r}\text { Infiltration } \\
\text { rate }\left(\mathrm{m} \mathrm{s}^{-1}\right)\end{array}$ \\
\hline 9 & 0.501 & 0.418 & 0.244 & $3.4 \mathrm{E}-06$ \\
18 & 0.474 & 0.367 & 0.162 & $1.04 \mathrm{E}-06$ \\
16 & 0.46 & 0.378 & 0.219 & $1.9 \mathrm{E}-06$ \\
33 & 0.472 & 0.35 & 0.144 & $1.04 \mathrm{E}-06$ \\
3 & 0.441 & 0.295 & 0.117 & $3.6 \mathrm{E}-05$ \\
25 & 0.473 & 0.408 & 0.255 & $6.9 \mathrm{E}-08$ \\
\hline
\end{tabular}

Medway catchment are derived from the Hydrology of Soil Types (HOST, see Table 1), provided by the National Soil Resources Institute (NSRI) in the UK.

These data clearly indicate that the recessions period with SST setting was much faster than the observation, possibly due to less resilience from a single-soil-type setting and the shallow depth of soil layer in the model. Consequently, multiple soil types and the increment depth of the soil layer were introduced to the model while the recession of the flood was improved. Additionally, the most critical performance criterion for the model, the Nash-Sutcliffe efficiency (NSE), increases from 0.68 (SST) to 0.82 (MST).

\subsection{The settings of a coupled UKV-HYPE case study}

The UKV model is set to make $36 \mathrm{~h}$ forecasts with a highresolution inner domain $(1.5 \mathrm{~km}$ grid boxes) over the area of forecast interest, separated from a coarser grid $(4 \mathrm{~km})$ near the boundaries by a variable resolution transition zone. This variable resolution approach allows the boundaries to be moved further away from the region of interest, reducing unwanted boundary effects on the forecasts.

Part of the motivation of using such resolution is to improve forecasts of convective rainfall. The variable resolution model with $1.5 \mathrm{~km}$ grid length over the UK (although increasing to $4 \mathrm{~km}$ at the edges of the domain) enables the 


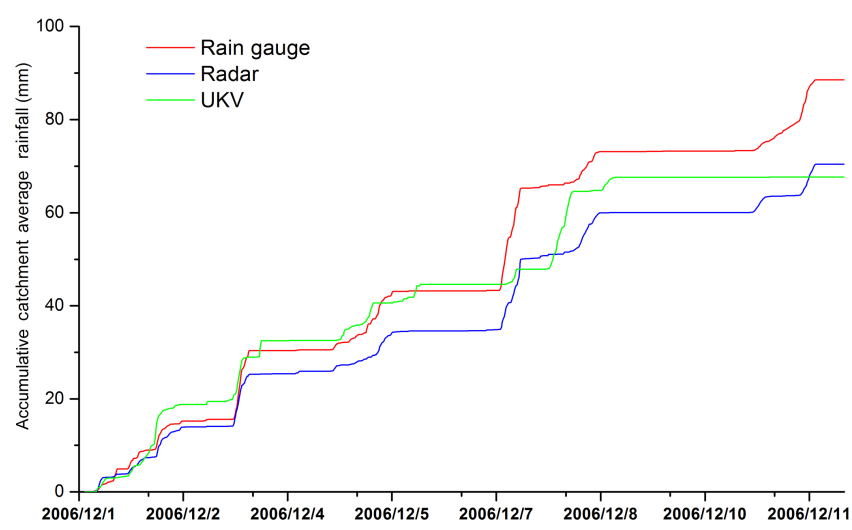

Figure 3. The comparison of accumulative catchment average rainfall (event December 2006).

boundaries of the model to be pushed further away from the area of interest at lower cost, and also enables reduction of the resolution mismatch with the driving $(12 \mathrm{~km})$ model. The UKV rainfall estimation produced by the Unified Model is used as the input for the HYPE model, which provides the cornerstone to the coupled UKV-HYPE model.

\section{Results and discussions}

Four flood events were selected to evaluate the performance of UKV rainfall products through HYPE hydrological model, by comparing the simulated streamflow driven by rain-gauge measurements, NIMROD radar rainfall estimates, and UKV rainfall data. For the first flood event, there was around $100 \mathrm{~mm}$ depth of precipitation over the Upper Medway catchment during 1 to 13 December 2006, according to the rain-gauge rainfall record.

Figure 3 shows the rainfall comparison on the accumulation of catchment average rainfall over the flood period. The UKV rainfall products had quite a good agreement with raingauge measurements before the high peak flow occurred on 7 December 2006, in terms of the accumulative catchment average rainfall. However, the hydrological simulations illustrated in Fig. 4 indicate that the rain-gauge measurements outperform the UKV rainfall product, especially on peakflow simulations.

Figure 4 shows the comparison of the hydrological model performances driven by three different rainfall products in the entire event. The NIMROD radar rainfall estimates and UKV rainfall products were underpredicted on all the peak flows, especially on the highest peak flow that occurred around 8 December 2006, compared with the rain-gauge measurements. However, the UKV rainfall products have very similar performance with radar rainfall estimates, on the peak-flow volume and the time of the peak, which implies that the high-resolution NWP rainfall products are as good as the radar rainfall estimates in this flood event.

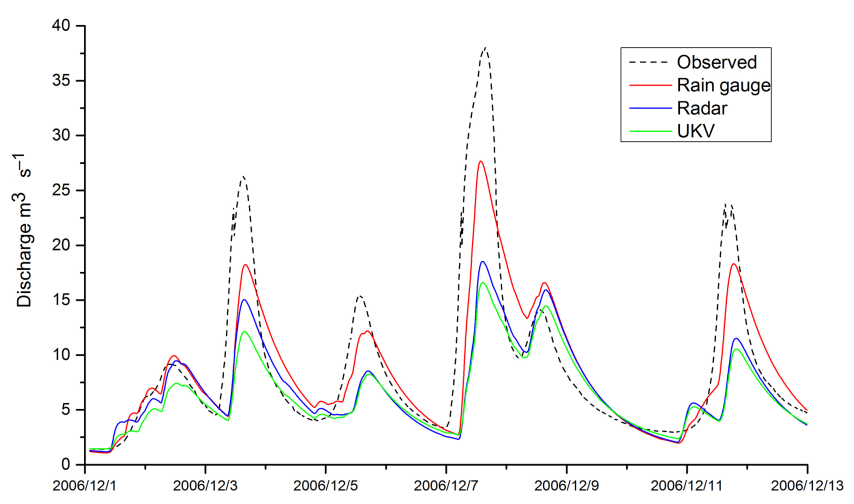

Figure 4. The comparison of flow simulation in HYPE (event December 2006).

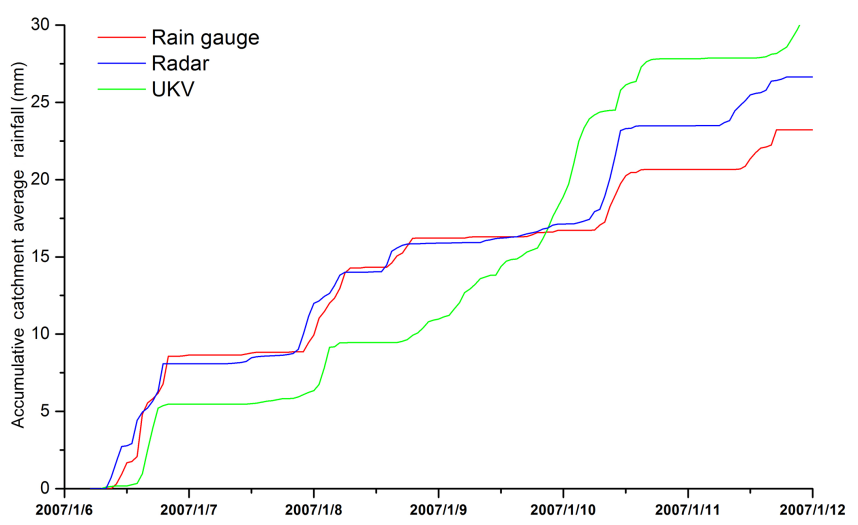

Figure 5. The comparison of accumulative catchment average rainfall (event January 2007).

For the second flood event, the comparison of accumulative catchment rainfall is shown in Fig. 5. The trends on the rainfall data are reasonably good across all three data sets. The UKV rainfall data do however pick up some exaggerated noisy peaks over the period between 9 and 10 January 2007.

Figure 5 also shows that the NIMROD radar data produced more rainfall depth over the catchment than rain-gauge measurements, but less than the UKV rainfall. In addition, it shows similar rising cumulative rainfall for this event between all three data sets, and particularly between rain-gauge measurements and radar rainfall estimation up to 10 January. In contrast, one notes that the UKV rainfall underestimates rain-gauge and radar data sets before 10 January, but with a similar rising trend. Departure arises subsequently between all three data sets, with UKV rainfall providing the extreme outcome.

The performance of UKV rainfall in the HYPE model simulation for the January 2007 flood event of Fig. 6 shows that the peaks and troughs are reasonably well represented against the observed data up to 10 January, after which the fourth peak is overestimated, and thus so is the final peak. The radar 


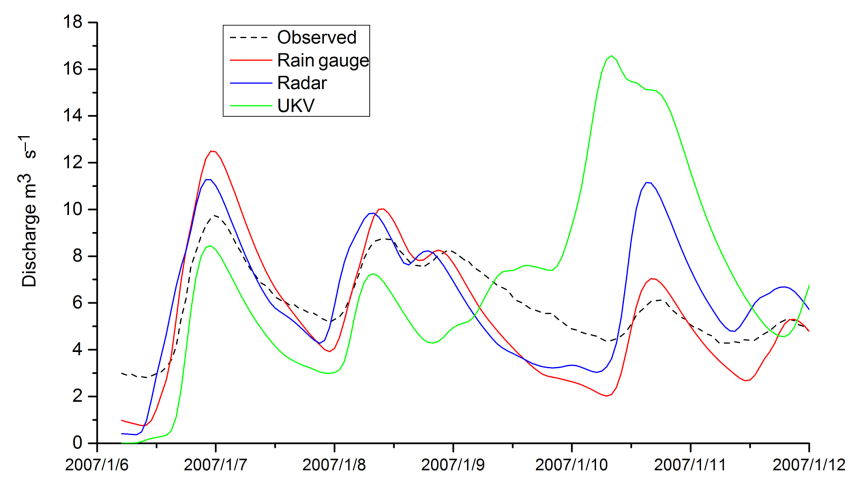

Figure 6. The comparison of flow simulation in HYPE (event January 2007).

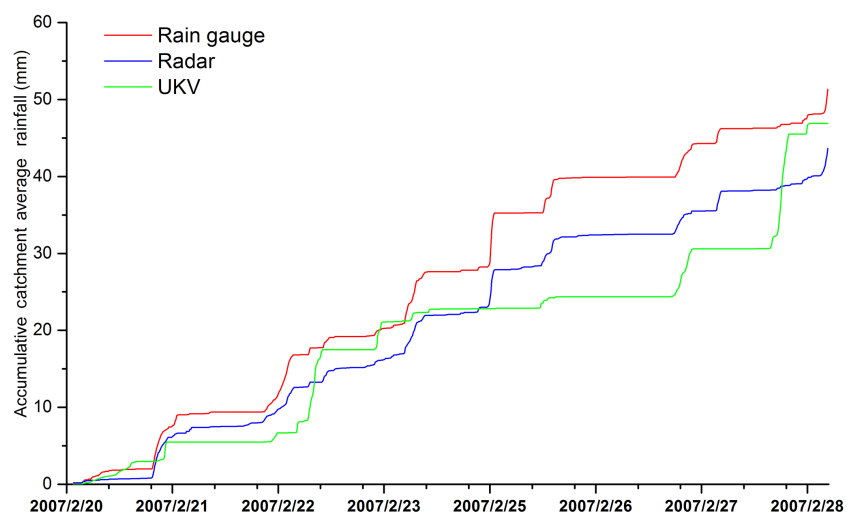

Figure 7. The comparison of accumulative catchment average rainfall (event February 2007).

data suffer likewise, over the final two peaks, which are better captured by the rain-gauge data. The rain-gauge data do however underestimate the observed data output over this period.

During the third flood event, there was a $50 \mathrm{~mm}$ rainfall depth in total over the catchment, recorded by the rain gauges, which triggered the highest discharge at the catchment outlet of about $25 \mathrm{~m}^{3} \mathrm{~s}^{-1}$ during the flood period. In terms of the cumulative catchment rainfall, the rain-gauge measurement produced more precipitation than the UKV rainfall, followed by the radar rainfall estimation.

However, Fig. 7 shows that the UKV rainfall product did not capture the trend of accumulative rainfall over the catchment, and therefore totally missed the two flow peaks after 24 February 2007 (illustrated in Fig. 8) compared with the raingauge measurement and radar rainfall estimates. The raingauge data outperform the radar data in this whole event, of which all the peak flows are better captured. However, the rain-gauge data do underestimate the observed data output over this period.

During the final event of July 2007, in terms of the flood magnitude, there was around $80 \mathrm{~mm}$ precipitation recorded by the rain gauges over 4 days which caused over $40 \mathrm{~m}^{3} \mathrm{~s}^{-1}$

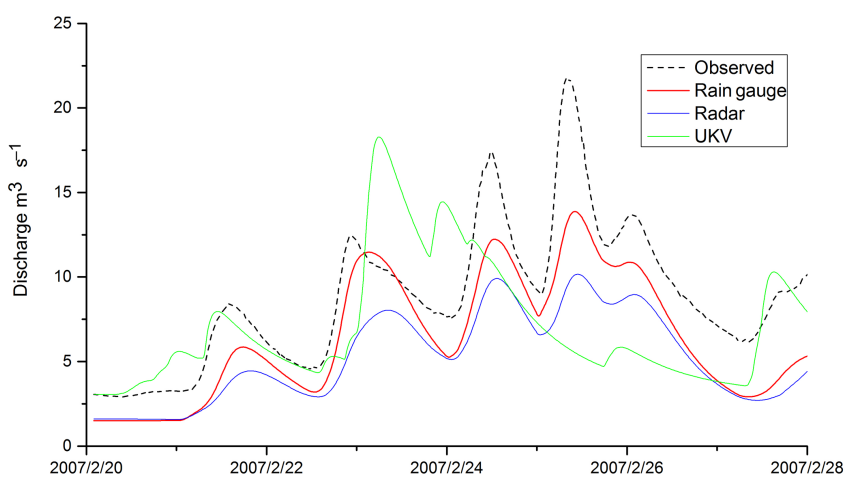

Figure 8. The comparison of flow simulation in HYPE (event February 2007).

discharge at the catchment outlet. It can be regarded as a similar case to the first flood event on December 2006, where the recorded streamflow was also around $40 \mathrm{~m}^{3} \mathrm{~s}^{-1}$, triggered by around $100 \mathrm{~mm}$ of precipitation in the catchment over 12 days. However, there were no other peaks before the highest flow appeared in this event and the peak only lasted 1 day, which implied that this was a flash flood (sudden high peak flow over a short period). It can also be identified from Fig. 9, which clearly showed that there was a significant increase (over $40 \mathrm{~mm}$ difference) on 20 July for the accumulative catchment precipitation calculated from all rainfall measurements and rainfall estimation products, especially during the period from 20 July at 08:00 LT to 20 July 2007 at 11:00 LT, when over $30 \mathrm{~mm}$ of precipitation fell on the catchment in $3 \mathrm{~h}$, detected from the rain-gauge network.

Considering the differences between the rain-gauge measurements and radar rainfall estimates, the precipitation estimated from radar reflectivity could be heavily attenuated. After being converted to Cartesian format, the details of the signal were further smoothed by the averaging process, which could explain the reason that the radar rainfall estimates underestimated a lot more than rain-gauge measurements. Additionally, because the model rainfall input for HYPE is the catchment average precipitation, the rainfall distribution and heterogeneities are not simulated, so that all the modelled flow was not comparable with the observation in this extreme rainfall flood event.

The flow simulation shown in Fig. 10 appears to pick up an exaggerated peak in the UKV rainfall through HYPE model simulation after the first day (16 July 2007), which is not reflected in the other data sets. This early disturbance influences the early undershoot of the observed-data first peak (at 21 July 2007), and the overshoot of the observed-data second peak (before 22 July 2007). Notably, rain-gauge data output overshoots the observed-data first peak, whilst NIMROD radar data output provides an undershoot; both undershoot the observed-data second peak. This is rather a testing event with only one single main flood event to sharply capture. Clearly, one would need to investigate further in this instance 


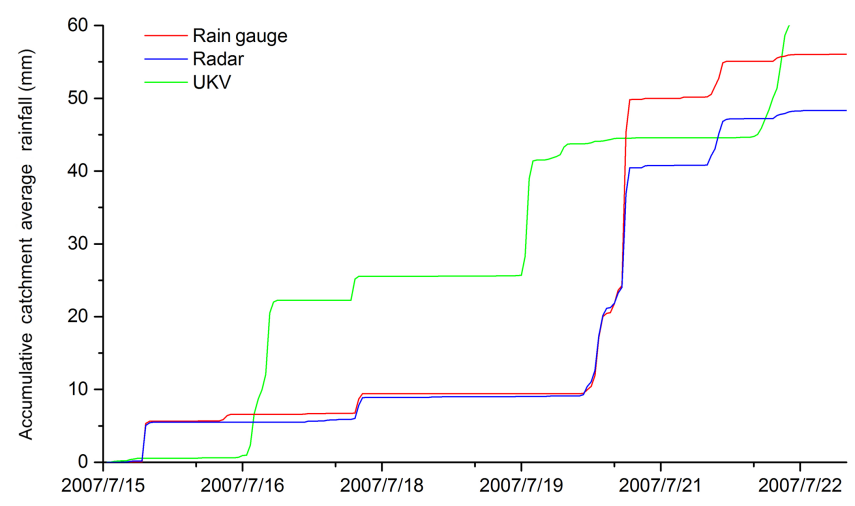

Figure 9. The comparison of accumulative catchment average rainfall (event July 2007).

as to why the early disturbance has arisen for UKV output in this case, and provide more data evidence to prove or refute this particular finding. Further case study events would help clarify this issue, as the January 2007 event did not show this.

\section{Conclusions}

This paper describes a recent effort to integrate both the driver NWP models and the impact analyser-hydrological model on a single HPC platform to support better and more refined studies on extreme weather impacts. What distinguishes this study from others is it is first time that modellers are able to simulate the entire system, ranging from the global circulation down to a target catchment, for an impact study. This study also explores the feasibility of building weather and climate services together with the impactoriented analysis on a single platform, and what can be done if this is not feasible: for example, how computing resources can be re-arranged to deal with the issues.

The initial idea of this study was in fact to include a whole system model including the UKV, data processing, and hydrological models on an HPC platform. This differs from the usual approach of getting the IC/BC (initial condition/boundary condition) from a weather centre and then running a limited area model such as WRF and then some hydrological simulations. Further, it aimed to fully integrate a hydrological model component into the UKV, which is not revealed by this paper yet, but it will form the basis for extension into a two-way coupling system, which will be developed further in the future. Therefore, this study aimed to construct and run both NWP and the hydrological model, either simultaneously or on the same hardware infrastructures, to achieve more effective interaction and communication, so that the potential of fully coupled NWP-hydrological forecasts on a single computer platform is explored, and firsthand knowledge on fully integrated hydro-meteorological modelling can be obtained.

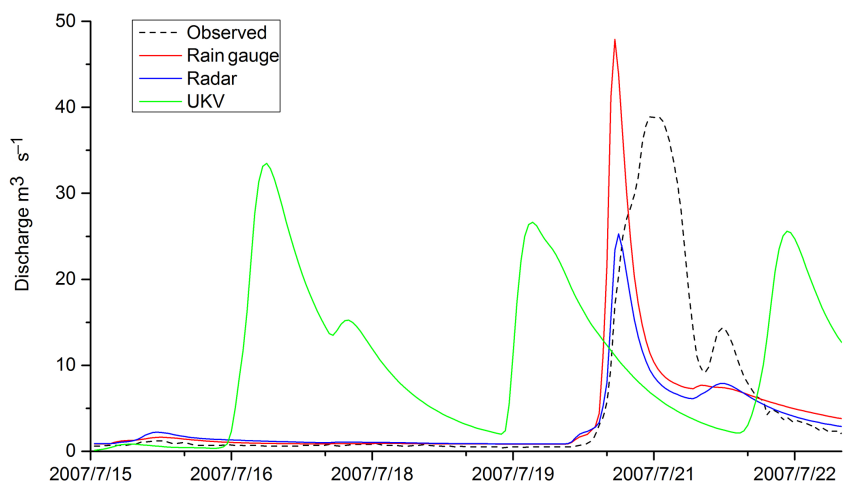

Figure 10. The comparison of flow simulation in HYPE (event July 2007).

The study finds that when running the entire system on a reasonably powerful HPC platform, the overall time frame does not yet allow for a real-time simulation even without the most complex and demanding data simulation part. It is therefore suggested that the components responsible for large scale simulation, such as global and European areas, should remain at national weather service centres where dedicated HPC resources can deal with the demand as they already have been doing. However, it is still possible to have a highresolution version with less geographical coverage running on a general-purpose HPC platform together with the impact analysing model such as a hydrological model and further inundation models. This configuration also allows for finer control and/or tuning of the models to fit various purposes.

The other main purpose of this study is to gain sight of how a common hydrological model can utilize the highresolution precipitation (among others) forecast and simulation in an impact study of extreme weather events. It is encouraging to find that even without fine-tuning, such as using various parameterization schemes, the coupled hydrometeorological was still able to capture the major flood peaks with much longer lead time compared with the conventional gauge- or radar-driven forecast (2-3 days vs. 2-3h). The high-resolution UKV rainfall shows some promising agreement with rain-gauge measurements and radar estimation in the first 2-3 days in this flood event, both in the average catchment rainfall amount and hydrological simulation in HYPE.

The study also identified uncertainties associated with precipitation forecast, particularly that it will increase as the forecast horizon goes beyond 3 days. For example, the latter part of the flood event was not represented well by the HYPE model simulation using the UKV rainfall, compared with those using other sources of rainfall, e.g. radar and rain gauges. This is, however, understandable and consistent with our previous studies using other models; see, for example, Seyoum et al. (2013). Apparently, other more complicated uncertainty-aware techniques need to be applied in 
this model coupling configuration, which, in fact, is the key research topic for further studies.

Overall, the primary value of this study is in making sure that the high-resolution UKV can be used to drive hydrological models like HYPE; and secondly, the study demonstrates that it is possible that with a moderate resources requirement, a fully integrated system can be established to benefit from independent data assimilation/NWP coupled with hydrological models. Although many deficiencies (such as uncertainty) still exist in such a system, as they do in many WRF-related studies, the ability to simulate from source (atmospheric observations) to end (flow simulation) means that these issues will be addressed more efficiently in the future.

Consequently, the following recommendations for future work are made:

1. The study needs to be repeated and extended, as more data sets become available from UKV.

2. The impact of the high-resolution new radar data needs to be explored in the context of distributed hydrological modelling.

3. The UKV rainfall needs to be fully assessed by various lead times and ensemble simulations, which encapsulate uncertainty generation and propagation through complex "cloud to catchment" or "Whole Systems Modelling" concepts.

\section{Data availability}

The source code of hydrological model HYPE can be obtained from the Swedish Meteorological and Hydrological Institute (SMHI); the research license of Unified Model (UM) and the UKV suite can be applied through the Met Office in the UK. The NIMROD radar rainfall data can be requested and obtained from the British Atmospheric Data Centre (BADC); the hydrological data, including the rain gauge measurements and flow records, are managed by UK Environment Agency. The catchment characteristic data can be found in Sect. 2 .

Acknowledgements. This study was partly funded under the Knowledge Transfer Partnership scheme, between Fujitsu Europe Laboratories Ltd and Swansea University, acting through support from Innovate UK (KTP009201) and the Welsh Government (GON CFI 468). The authors D. Zhu and S. Echendu would like to gratefully acknowledge this support.

The study is also partly supported under the ongoing research initiative, "Welsh Extreme Weather Study". The HPC resources were provided by HPC Wales (HPCW179). Access to the UM/UKV was supported by UK Met Office, under license agreement UML0030, which is also gratefully acknowledged. The NIMROD data were provided by the UK Met Office. The catchment soil data were provided by National Soil Resources Institute. The HYPE model and continuous modelling technical support were provided by the
Swedish Meteorological and Hydrological Institute. Finally, our thanks go to the National Centre for Atmospheric Sciences for their technical support and access to HPC resources.

Edited by: Q. Chen

Reviewed by: two anonymous referees

\section{References}

Cloke, H. L. and Pappenberger, F.: Ensemble flood forecasting: A review, J. Hydrol., 375, 613-626, 2009.

Dudhia, J.: A non-hydrostatic version of the Penn State/NCAR mesoscale model: validation tests and simulation of an Atlantic cyclone and cold front, Mon. Weather Rev., 121, 1493, doi:10.1175/1520-0493(1993)121<1493:ANVOTP>2.0.CO;2, 1993.

Golding B. W.: NIMROD: a system for generating automated very short range forecasts, Met. Appl., 5, 1-16, 1998.

Grell, G., Dudhia, J., and Stauffer, D.: A description of the fifth generation Penn State/NCAR Mesoscale Model (MM5), NCAR Technical Note, NCAR/TN-398CSTR, 117 pp., 1994.

Jasper, K., Gurtz, J., and Lang, H.: Advanced flood forecasting in Alpine watersheds by coupling meteorological observations and forecasts with a distributed hydrological model, J. Hydrol., 267, 40-52, 2002.

Kunstmann, H. and Stadler, C.: High resolution distributed atmospheric-hydrological modelling for Alpine catchments., J. Hydrol., 314, 105-124, 2005.

Schulla, J. and Jasper, K.: Model Description WASIM-ETH (Water Balance Simulation Model ETH), ETH-Zurich, Zurich, 2000.

Seyoum, M., van Andel, S., Xuan, Y., and Amare, K.: Precipitation Forecasts for Rainfall Runoff Predictions: A case study in poorly gauged Ribb and Gumara catchments, upper Blue Nile, Ethiopia, Phys. Chem. Earth, 61-62, 43-51, doi:10.1016/j.pce.2013.05.005, 2013.

Smith, K. T. and Austin, G. L.: Nowcasting precipitation - a proposal for a way forward, J. Hydrol., 239, 34-45, 2000.

Westrick, K., Storck, P., and Mass, C.: Description and evaluation of a hydrometeorological forecast system for mountainous watersheds, Weather Forecast, 17, 250-262, 2002.

Wigmosta, M. S., Vail, L. W., and Lettenmaier, D. P.: A distributed hydrology-soil-vegetation model for complex terrain, Water Resour. Res., 30, 1665-1679, 1994.

Xuan, Y., Cluckie, I. D., and Wang, Y.: Uncertainty analysis of hydrological ensemble forecasts in a distributed model utilising short-range rainfall prediction, Hydrol. Earth Syst. Sci., 13, $293-$ 303, doi:10.5194/hess-13-293-2009, 2009.

Yarnal, B., Lakhtakia, M. N., Yu, Z., White, R. A., Pollard, D., Miller, D. A., and Lapenta, W. M.: A linked meteorological and hydrological model system: the Susquehanna River Basin Experiment (SRBEX), Global Planet. Change, 25, 149-161, 2000.

Zhu, D. and Cluckie, I. D.: A preliminary appraisal of Thurnham Dual Polarisation Radar in the context of hydrological modelling structure, J. Hydrol. Res., 43, 736-752, 2012.

Zhu, D., Xuan, Y., and Cluckie, I.: Hydrological appraisal of operational weather radar rainfall estimates in the context of different modelling structures, Hydrol. Earth Syst. Sci., 18, 257-272, doi:10.5194/hess-18-257-2014, 2014. 